\title{
Stock Recommendation: Key Steps and Applied Models
}

\author{
Ziwen Chen \\ Business Administration\& Quantitative Economics Major, Paul Merge School of Business \& Social Science \\ Department, University of California, Irvine, 92612, United States
}

Keywords: Stock market, Stock recommendation, Analysis model

\begin{abstract}
It is common to select stocks for constructing a portfolio; however, not all investors understand how to evaluate stocks. Investing in a stock requires investors to understand the company by inspecting the company's financial reports and announcements; also, investors need to be prudent to make a bid. This essay is going to demonstrate the steps of evaluating a U.S. public company's stock, Keysights Technology, Inc. To generate a convincing stock research, analysists need to apply scientific methods. The idea is to set a target price of a company's stock price and argue whether and why the price could reach the target price or not. Then, analysists need to glean supporting evidences to have a conclusion. For example, the Keysights Technology, Inc’s stock price was \$37.56, and my goal price is $\$ 41.5$; hence, my argumentation will be centered in presenting the company's financial facts and applying financial models, which all supports that the company's stock price could be likely to reach the target. Hence, price setting needs to be rational. Analysists need to know that a stock might be not worth recommending, if it merely has a limited potential growth; generally speaking, a least $10 \%$ potential price growth is a reasonable threshold of recommending stocks.
\end{abstract}

\section{Company Highlights}

Key Financial Data. The stock evaluation starts from the understanding of the company. Analysists like to view the company's key financial data first from quantitative concerns. Although those key financial data cannot tell investors all stories, they are helpful in reflecting the company's financial performance. Therefore, it is necessary to find those data. I recommend analysists to visit Thomson One or Bloomberg to procure those information for pursuing constancy and accuracy.

I would like to recommend that analysists should not simply get those information; however, knowing how to interpret those data is more important. For example, when I attempted to analyze Keysights Technology Inc's stock, I want to know the company's enterprise value, the company's Beta, and the company's P/E ratio, which are all important information reflecting the company's financial valuation. Therefore, I believe that analysists need to absorb that information when recoding it, because analysists could have a rough picture of the company from these numbers.

\section{Industrial Overview and Competitive Position}

Besides knowing the company’s financial data and business description, analysists also need to locate the company in the industrial. I recommend visiting Thomson One and find the analysis prepared by other specialists, because it is proper to gather more information from outside resources. Industrial overview is a good resource, from which analysists could quickly realize the momentum of the industry. Therefore, analysists could locate the company in the industry, determining whether the company is in a good track or not. For example, Keysights Technology Inc. would have a benefiting motion in the industry due to its high R\&D expenses.

Additionally, Bloomberg proffers the supply chain of the company. The following chart summarizes the suppliers, competitors, and main customers of Keysights Technology, Inc. From the chart, analysists could also find the company's role in the industry. For example, using SWOT method, I summarized Keysights Technology Inc.'s competitive position based on its supply chain network. 


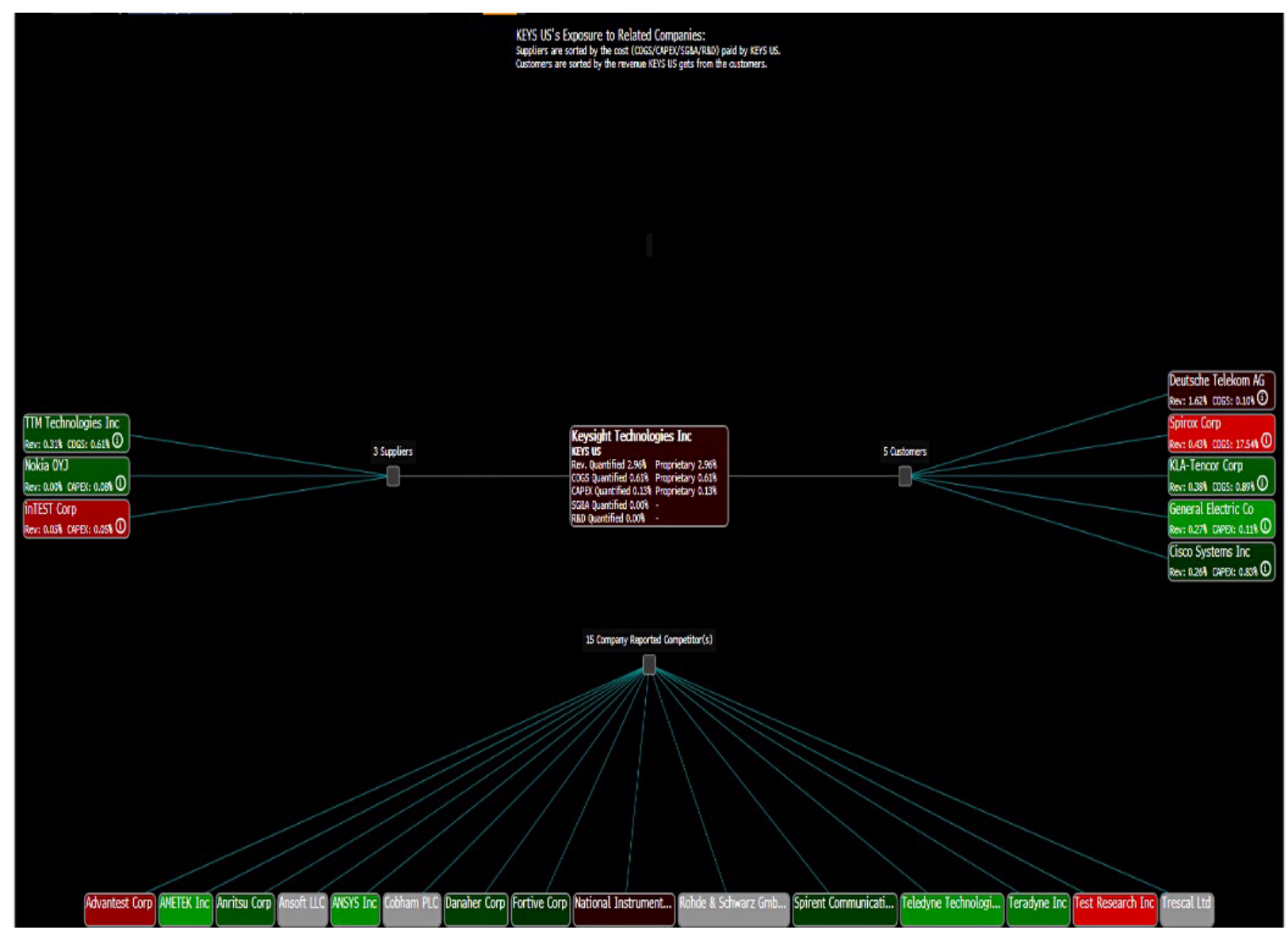

Figure 1. Key technology companies

\section{Valuation}

The second step is valuation. Financial analysists need to quantify data to have a direct measurement. I am going to introduce absolute valuation (DCF Model) and relative valuation (Bloomberg EQRV) in this step. Absolute valuation is the value evaluation concerning the perpetuity of the company itself, but the relative valuation is the comparison between the company and its competitors.

Relative Valuation - Bloomberg EQRV Function \& Thomson One. Absolute valuation provides a numerical estimation to the analysis, but Relative valuation concentrates on the comparision between the company and its competitors. From the previous industry overview and competitive position, analysists have already had a basic idea of the company's posisition in the industry; howevere, for pursuing convincing analysis, financial analysists need to offer quantified data. Therefore, analysists can apply Bloomberg EQRV function for gathering detailed information about the company and its competitors. For example, I made two claims to support the goal setting based on KeysightsTechonology, Inc.'s relative equity valuation. The first claim is that the current PE is $16.1 \mathrm{x}$, but I estimate that its $\mathrm{P} / \mathrm{E}$ will be lower than $15.2 \mathrm{x}$ which is +1 standard deviation from multiple averages. Although P/E subtracts, the estimated growth of Keys's revenue supports the target price, so I think that the current price is undervalued on multiple basis. The second claim is that the current $\mathrm{EV} / \mathrm{Rev}$ ratio is $2.3 \mathrm{x}$ which is exactly the +1 standard deviation from the multiple average. I think Key's EV/Rev will be stable in the range from 2.1 to 2.3, supported by the potential increasse in Key's EV and Rev. 


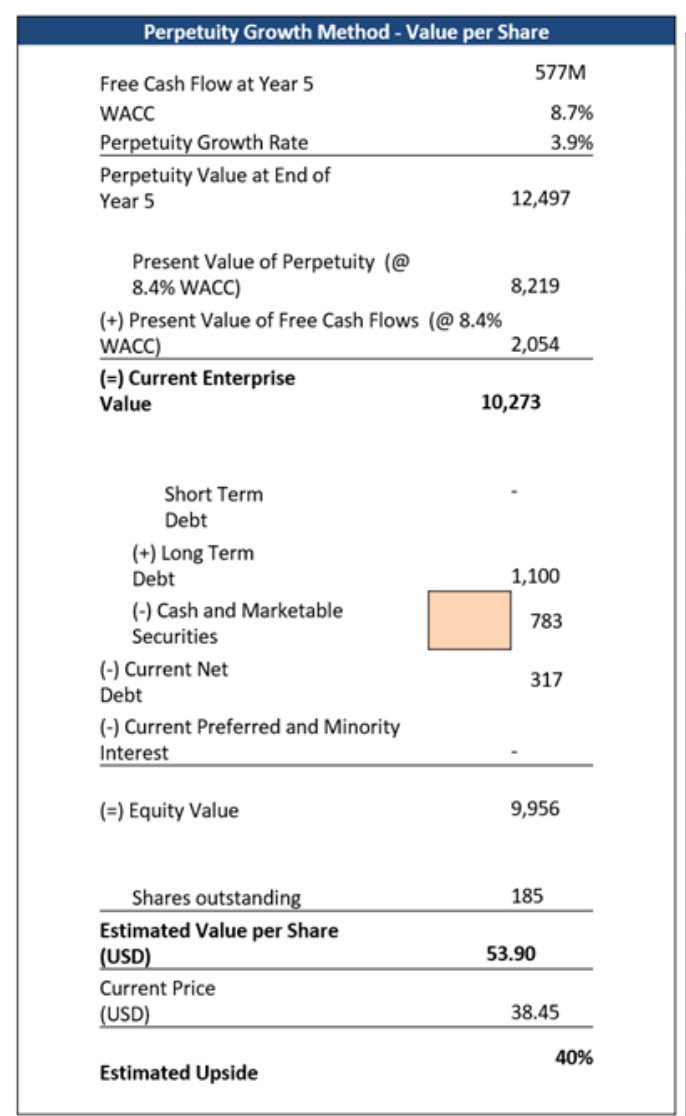

\begin{tabular}{|c|c|c|c|c|c|c|}
\hline \multicolumn{7}{|c|}{ Perpetuity Growth Method } \\
\hline \multicolumn{4}{|c|}{ Current Price (USD) } & & & 38.45 \\
\hline \multicolumn{4}{|c|}{ Consensus Price Target } & & & 42.00 \\
\hline \multicolumn{4}{|c|}{ DCF Estimated Value per Share (USD) } & & & 53.90 \\
\hline \multicolumn{4}{|c|}{ DCF Estimated Upside } & & & $40 \%$ \\
\hline \multirow{13}{*}{$\begin{array}{l}\text { Discount } \\
\text { Rate } \\
\text { (WACC) }\end{array}$} & & \multicolumn{5}{|c|}{$\begin{array}{l}\text { Perpetuity } \\
\text { Growth }\end{array}$} \\
\hline & & $2.9 \%$ & $3.4 \%$ & $3.9 \%$ & $4.4 \%$ & $4.9 \%$ \\
\hline & $7.7 \%$ & 55.81 & 61.43 & 68.52 & 77.76 & 90.29 \\
\hline & $8.2 \%$ & 50.38 & 54.85 & 60.36 & 67.32 & 76.39 \\
\hline & $8.7 \%$ & 45.88 & 49.51 & 53.90 & 59.31 & 66.15 \\
\hline & $9.2 \%$ & 42.10 & 45.1 & 48.67 & 52.98 & 58.29 \\
\hline & \multirow[t]{2}{*}{$9.7 \%$} & 38.88 & 41.4 & 44.34 & 47.84 & 52.08 \\
\hline & & $2.9 \%$ & $3.4 \%$ & $3.9 \%$ & $4.4 \%$ & $4.9 \%$ \\
\hline & $7.7 \%$ & $45 \%$ & $60 \%$ & $78 \%$ & $102 \%$ & $135 \%$ \\
\hline & $8.2 \%$ & $31 \%$ & $43 \%$ & $57 \%$ & $75 \%$ & $99 \%$ \\
\hline & $8.7 \%$ & $19 \%$ & $29 \%$ & $40 \%$ & $54 \%$ & $72 \%$ \\
\hline & $9.2 \%$ & $9 \%$ & $17 \%$ & $27 \%$ & $38 \%$ & $52 \%$ \\
\hline & $9.7 \%$ & $1 \%$ & $8 \%$ & $15 \%$ & $24 \%$ & $35 \%$ \\
\hline
\end{tabular}

Figure 2 and 3. Absolute Valuation - DCF Model

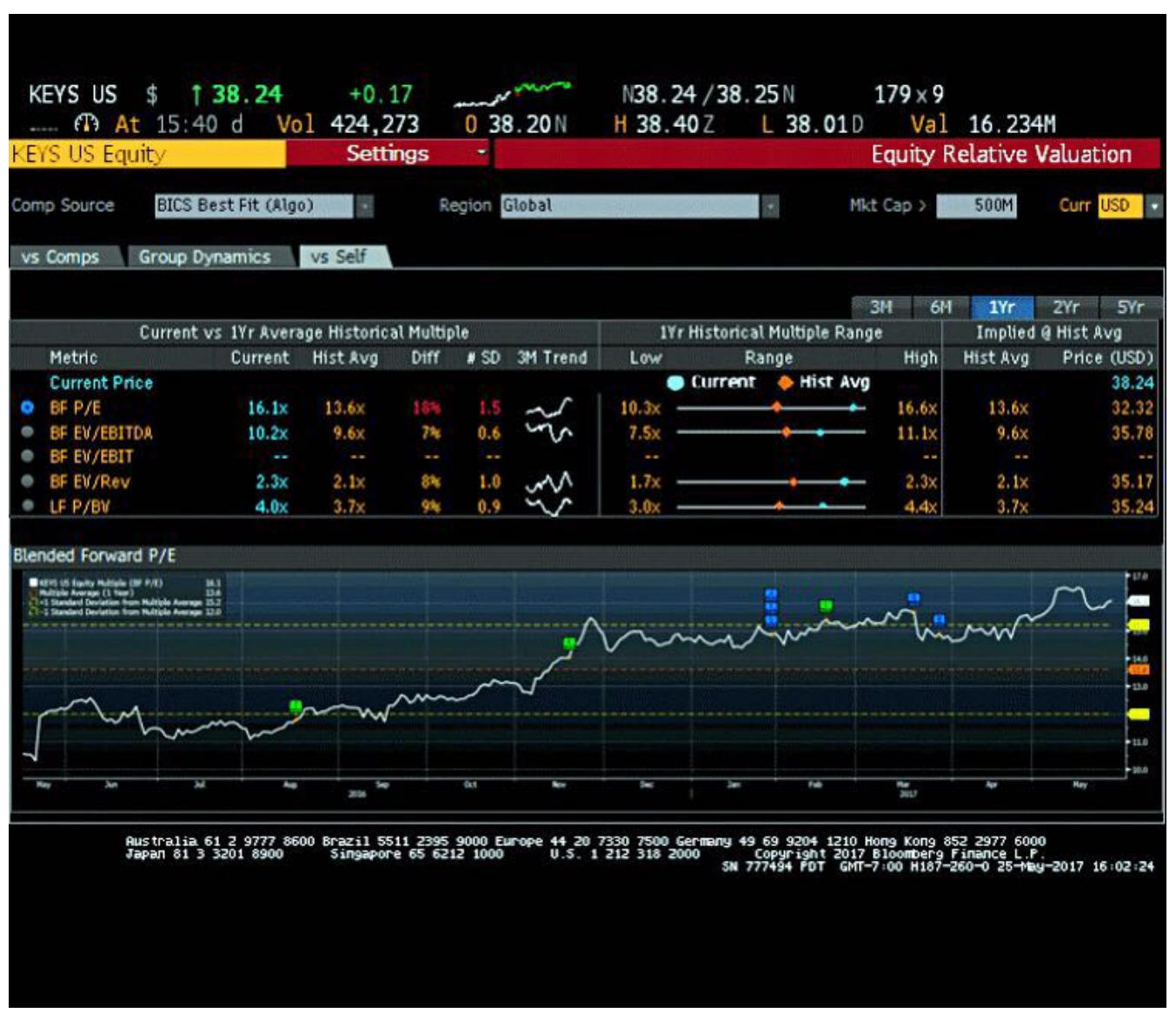

Figure 4. Detailed financial data 
For collecting more detailed financial data, Thomson One is a good source. The detailed financial data could be considered as the backup information in case of any numerical conflict.

\section{Investment Summary}

ESG Rating. ESG Rating is called "Board and Environmental, Social and Governance Ratings", which is used to reflect the company's efficiency. From ESG Rating, analysists can also realize whether the company improves its internal arrangement or not; so ESG Rating is a good resource helping analysists integrate company's internal control into consideration. For example, I conclude from Keysights Technology, Inc.'s ESG Rating that:

Its ESG disclosure score has been increased from 7.85 in 2014 to 45.5 in 2016 . Although it is still not optimal, it shows a huge improvement in its ESG ratings. Keysight Technologies, Inc.'s ISS Governance Quality Score as of May 1, 2017 is 4, which indicates a relative low risk. Most of the board members has experience prior to serving the Keysights Tech. They have been served in Agilent in some significant position such as COO and CFO.

This information indicates that Keysights Technology Inc. has a professional management team, and its operational governance also improves this year, which all supports that Keysights Tech Inc. has a stable and professional management.

Overall Summary. The final component is the overall summary of investing recommendation. In this part, analysists need to briefly but accurately proffer their opinions. It is necessary to restate the target price setting, main supporting assumptions, and the final suggestions (buy/sell/hold), so the analysis will be logical and complete.

Here is a quotation from my stock research showing the overall summary in each point:

Keysights Tech Inc. positioned for growth with a price target of $\$ 41.50$, representing a $2.68 \%$ increase in one year

Since the spin-out from Agilent at the end of 2014, KEYS has increased its R\&D spending from 12\% of Sales to $14 \%$ of sales. As 5 G ramps, we expect that KEYS will be able to demonstrate both a potential growth and a gain in market share.

It has been historically outperformed the estimates. The target price from the DCF will be \$53.92 with the current price is just $\$ 38.24$, indicating an underestimated value of its value per share.

From the financial analysis, the asset turnover is consecutively decreasing in four years, which indicates an increasing profit margin.

Although its EPS has lowered significantly in the past three years, the reason is partially due to its current split of diluted No. of shares by $\$ 1 \mathrm{M}$. Moreover, its revenue is estimated to grow significantly at $14.68 \%$ since 2016 to 2018 , which will also contribute to decreasing its PE ratio.

Overall, after the quantitative and qualitative analysis, Key sights is well worth investing

\section{References}

[1] Yoo Y, Park H. The Informational Content OfChanges In Stock Recommendation: Chaebol Vs. Non-ChaebolAffiliatedAnalysts[J]. Journal of Applied Business Research (JABR), 2016, 32(6): 1687-1696.

[2] Chang C H. Exploring stock recommenders' behaviorandrecommendationreceivers' sophistication[J]. Journal of Economics andFinance, 2017, 41(1): 1-26.

[3] Geva T, Zahavi J. Empiricalevaluationof an automatedintraday stock recommendation system in corporating both market data and textual news[J]. Decision support systems, 2014, 57: 212-223.

[4] Jin S, Sun T, Song B. A Stock RecommendationAlgorithmbase on the Trading Behaviorof Stock Investors[J]. International Journal of Applied MathematicsandStatistics ${ }^{\mathrm{TM}}$, 2013, 48(18): 238-244. 